\title{
Osteoblast Behavior on Novel Porous Polymeric Scaffolds
}

\author{
Juan Manuel Fernandez ${ }^{1,2}$, M. Susana Cortizo², \\ Ana M. Cortizo ${ }^{1, *}$, and Gustavo A. Abraham ${ }^{3}$ \\ ${ }^{1}$ Grupo de Investigación en Osteopatías y Metabolismo Mineral (GIOMM), Departamento de Ciencias Biológicas, \\ Facultad de Ciencias Exactas, Universidad Nacional de La Plata, La Plata, Argentina \\ ${ }^{2}$ Instituto de Investigaciones Fisicoquímica Teóricas y Aplicadas (INIFTA), Facultad de Ciencias Exactas, \\ Universidad Nacional de La Plata, CC 16 Suc. 4, La Plata, Argentina \\ ${ }^{3}$ Instituto de Investigaciones en Ciencia y Tecnología de Materiales (INTEMA), \\ UNMdP-CONICET, J.B. Justo 4302, 7600 Mar del Plata, Argentina
}

\begin{abstract}
Current efforts in bone tissue engineering have as one focus the search for a scaffold material that supports osteoblast proliferation, matrix mineralization, and, ultimately, bone formation. Electrospraying of polymer solutions has enabled the engineering of porous materials to meet current challenges in bone replacement therapies. Porous scaffolds of poly $(\varepsilon$-caprolactone)/poly(diisopropyl fumarate) compatibilized blend for bone tissue engineering were obtained by electrospraying technique in order to create a better osteophilic environment for the growth and differentiation of osteoblasts. Non-porous films having smooth surface were obtained by casting and used for comparison purposes. Studies on cell-scaffold interaction were carried out by culturing two osteoblastlike cell lines, MC3T3E1 and UMR106, on three-dimensional scaffolds and two-dimensional films. Growth, proliferation, and differentiation (alkaline phosphatase activity) of osteoblasts, were assessed. Scaffolds displayed a highly porous structure with interconnected pores formed by polymer microparticles, and higher hydrophobicity than the observed in non-porous films. The adhesion, proliferation and alkaline phosphatase activity of cells grown on the porous scaffolds increased significantly in comparison to those observed on flat films. The rough surface morphology of this novel scaffold enhances osteoblast response. These results suggest that electrosprayed porous scaffolds may be potentially used as tissue engineering scaffolds with high bone regenerative efficacy.
\end{abstract}

Keywords: Electrospraying, Bone Tissue engineering, Adhesion, Proliferation, Alkaline Phosphatase.

\section{INTRODUCTION}

Current challenges in the field of tissue engineering lie in the design of biocompatible scaffolds of natural, synthetic or composite biomaterials that mimic the structural and biological functions of natural extracellular matrix (ECM). ${ }^{1,2}$ There are many clinical reasons to develop bone tissue-engineering alternatives, including the need for better filler materials that can be used in the reconstruction of large orthopaedic defects and the need for orthopaedic implants that are mechanically more suitable to their biological environment. ${ }^{3}$ Appropriate three-dimensional scaffold is an essential component for a tissue engineering

\footnotetext{
*Author to whom correspondence should be addressed.
}

strategy. Besides the choice of adequate materials, the macro and micro-structural properties of the materials are of major importance. Such properties affect not only cell survival, signalling, growth, propagation, and reorganization but also their gene expression and the preservation, or not, of their phenotype. ${ }^{4}$

Although different fabrication methods have been reported to prepare highly porous artificial matrices, ${ }^{2,5}$ cost-effective techniques that can yield scaffolds that are capable of directing healthy and homogeneous tissue development are increasingly needed.

Electrospraying is a novel electrohydrodynamic fabrication method that increasingly attracted the attention of researchers who are interested in building micro- or nanometer architectures with a controllable microstructure 
such as functional tissue scaffolds, drug delivery carriers, patterned biochips, and bioactive films or coatings. ${ }^{6}$ This technique produces particles with dimensions that range from micrometers to nanometers depending on the processing parameters, and represents an exciting opportunity to scaffold fabrication for biomedical applications. The principle of electrospraying is essentially the same as that of electrospinning. In a typical process, a solution is fed to a nozzle and a droplet forms at the nozzle. When the droplet is exposed to a strong electric field, a charge is induced on the surface of the droplet. Influenced by the electrostatic field, the droplet at the tip of nozzle forms a conical shape. From the tip of this cone, a charged jet of solution is propelled to the grounded collector. Electrospraying results from the interaction of bulk and surface electrohydrodynamic forces breaking the jet into droplets. Due to surface tension the jet fragments acquire a spherical shape before being deposited on a grounded substrate. ${ }^{7}$ In electrospinning the jet creates a solid micro/nanofiber. ${ }^{8-10}$ These electrohydrodynamic processes are affected by a multitude of variables, such as physicochemical properties (polymer molecular weight and concentration, solvent, conductivity, surface tension), and processing parameters (applied voltage, needle to collector distance and solution flow rate). The most important variable distinguishing electrospraying and electrospinning is the polymer concentration of the solution used in the process. The droplet generation is a consequence of using a lower concentration of polymer solution that what is used in electrospinning. ${ }^{7,11}$

Electrospray deposition technology can be used to design scaffold materials, which will mimic the native ECM for guiding cell growth or tissue generation. Electrospraying was also reported as a useful alternative method for surface modification of biomedical implants, changing the surface properties of implants using superior coatings. ${ }^{12}$ This technique also is attractive for drug delivery applications, allowing the delivery of bioactive agents with a variety of release profiles. ${ }^{12}$

Synthetic biodegradable polymers are demonstrated to be excellent materials for use as scaffolds in different areas of tissue engineering and regenerative medicine. ${ }^{12}$ In previous works, Cortizo et al. ${ }^{14}$ have reported that films of poly( $\varepsilon$-caprolactone) (PCL) and poly(diisopropyl fumarate) (PDIPF) supported adhesion, proliferation and differentiation of UMR106 and MC3T3E1 osteoblast-like cell lines without evidence of cytotoxicity, suggesting that these polymers could be useful in bone tissue regeneration.

In the present work, a compatibilized blend of PCL and PDIPF with mechanical properties comparable to those of trabecular bone, intermediate degradation rate between the homopolymers, and demonstrated biocompatibility, ${ }^{15}$ was prepared and processed by electrospraying. The aim of this study was to characterize and to evaluate the activity of MC3T3E1 and UMR106 cells comparing its behavior on different substrates (porous scaffolds and flat films).

\section{MATERIALS AND METHODS}

\subsection{Synthesis and Characterization of Polymer Blends}

Poly(diisopropyl fumarate) (PDIPF) was synthesized by microwave-assisted radical polymerization using benzoyl peroxide as initiator. ${ }^{16}$ Briefly, $1 \mathrm{~g}$ monomer was added to a previously weighed amount of initiator $(30 \mathrm{mM})$ under nitrogen atmosphere into a $25 \mathrm{~cm}^{3}$ conical Pyrex flask closed by a septum. The reactor was subjected to different times and power of microwave irradiation using a domestic microwave oven (Zenith, ZVP-2819). After reaction, the polymers were isolated and purified by solubilisation in toluene and then it was precipitated dropped on methanol. The resulting blend was dried until constant weight was achieved. In this work a sample of weight-average molecular weight $M_{\mathrm{w}}=131 \mathrm{~kg} \mathrm{~mol}^{-1}$ and polydispersity index $\mathrm{PDI}=2.0$, was used. Poly $(\varepsilon$-caprolactone $)\left(\mathrm{PCL}, M_{\mathrm{w}}=\right.$ $\left.65 \mathrm{~kg} \mathrm{~mol}^{-1}\right)$ and $\mathrm{PDI}=1.4$, was purchased from Aldrich Chemical Co.

Compatibilized PCL/PDIPF blend (75:25 by weight) were obtained by using a Bandelin Sonopuls HD60 ultrasonic homogenizer at $20{ }^{\circ} \mathrm{C}$ as previously described. ${ }^{15}$

Average molecular weights and molecular weight distribution of the polymers were determined by size exclusion chromatography (SEC) using a gradient pump (Pharmacia, LKB-2249) attached to a Miran 1A infrared spectrophotometer detector at a wavelength of $5.75 \mu \mathrm{m}$. A set of $\mu$-Styragel columns, ranging in pore size $10^{5}, 10^{4}, 500$, $100 \AA$, conditioned at $25^{\circ} \mathrm{C}$ were used to elute the samples of $4-5 \mathrm{mg} \mathrm{mL}^{-1}$ concentration at $0.5 \mathrm{~mL} \mathrm{~min}{ }^{-1}$ HPLCgrade chloroform flow rate. Calibration curve was established using poly(methyl methacrylate) standards.

\subsection{Films and Scaffolds Preparation}

Polymeric films were prepared by solvent casting technique from chlorofom solutions $5 \% \mathrm{wt} / \mathrm{wt}$ and poured onto glass Petri dishes of $19.6 \mathrm{~cm}^{2}$. The solvent was allowed to evaporate at room temperature, and the resulting films were exhaustively dried under vacuum until constant weight was achieved.

Porous scaffolds were obtained by electrospraying technique. Solutions were prepared by dissolving PCL/PDIPF blend in chloroform $(4 \% \mathrm{wt})$. The clear solution was loaded into a standard $10 \mathrm{~mL}$ plastic syringe connected to a polyamide tube, the open end of which was attached to a blunt 18-gauge stainless steel hypodermic needle (I.D. = $0.838 \mathrm{~mm}$ ) used as the nozzle. A programmable syringe pump (Activa A22 ADOX S.A., Argentina) connected to the syringe controlled the flow rate. A high-voltage power source (ES30P, Gamma High Voltage Research Inc.) was used to charge the solution by attaching the electrode of positive polarity to the nozzle, and the grounding one to the aluminium collecting target covered with glass plates 


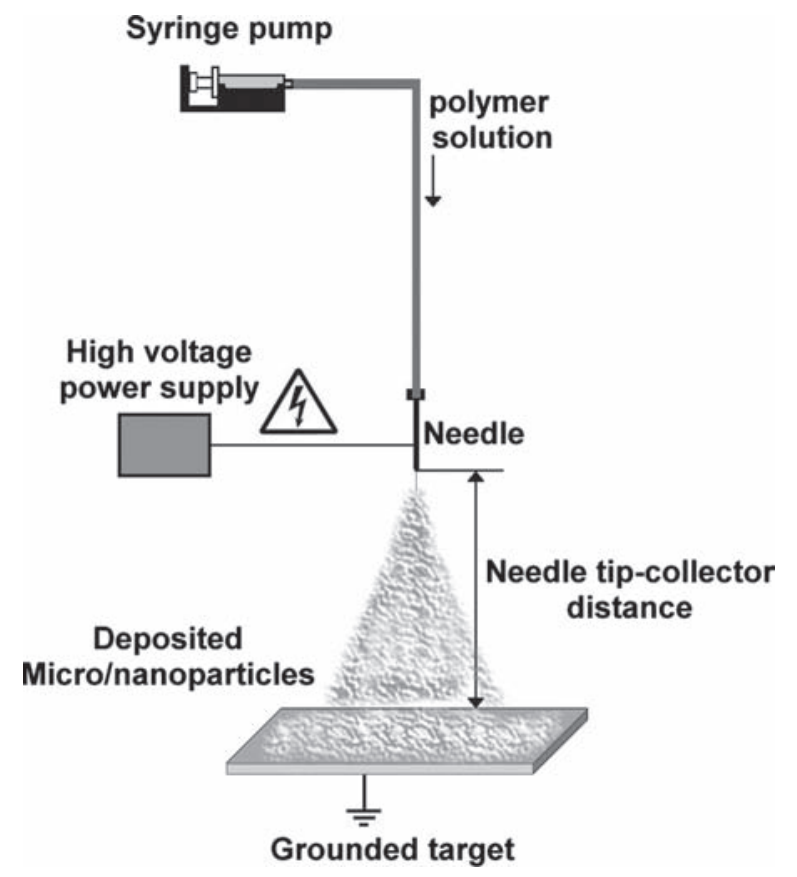

Fig. 1. Schematic diagram of an experimental setup for electrospraying solutions.

( $2.6 \mathrm{~cm}$ long $\times 1.8 \mathrm{~cm}$ wide). All experiments were carried out at room temperature in a chamber having a ventilation system. Solutions were electrosprayed at a positive highvoltage gradient of $0.7 \mathrm{kV} / \mathrm{cm}$ and a solution flow rate of $1.5 \mathrm{~mL} / \mathrm{h}$ during $10 \mathrm{~min}$. Figure 1 shows a schematic diagram of the electrospraying process. The glasses containing the scaffolds were dried under vacuum at room temperature to fully eliminate the residual solvent, and stored in a desiccator until use.

Both solution-cast films and porous scaffolds were sterilized by UV exposition for $2 \mathrm{~h}$. SEC confirmed that no degradation of the material had occurred during this treatment.

\subsection{Morphology Characterization}

Morphologies of plain and porous surfaces were qualitatively characterized by scanning electron microscopy (SEM). Samples were viewed under Philips 505 scanning electron microscope operated at an accelerating voltage of $20 \mathrm{kV}$. Polymeric surfaces were sputter coated with gold before viewing under SEM. The images were analyzed by using Soft Imaging System ADDA II.

\subsection{Contact Angle Measurements}

Water contact angle (WCA) measurements were carried out using a ramé-hart Model 500 goniometer (raméhart instrument co., USA) in the static contact angle mode. Double-distilled water was used in the measurement. Images were analyzed with DROPimage Advanced v2.2 software. All the tests were performed on the airfacing surfaces of the samples. At least six measurements on different positions on the sample surface were performed to calculate the mean static contact angle.

\subsection{Cell Culture and Incubation}

UMR106 rat osteosarcoma cells and MC3T3E1 mouse calvaria-derived cells were grown in DMEM containing $10 \% \mathrm{FBS}, 100 \mathrm{U} / \mathrm{ml}$ penicillin and $100 \mu \mathrm{g} / \mathrm{ml}$ streptomycin at $37{ }^{\circ} \mathrm{C}$ in a $5 \% \mathrm{CO}_{2}$ atmosphere. ${ }^{17}$ Cells were seeded on $75 \mathrm{~cm}^{2}$ flasks and sub-cultured using trypsinEDTA. The UMR106 cell line has been shown to conserve certain characteristics of differentiated osteoblastic phenotype. ${ }^{18}$ For the different experiments, cells were seeded over polymeric scaffolds and were cultured in $10 \%$ FBS-DMEM during different incubation periods. In the case of the pre-osteoblastic MC3T3E1 line, cells were induced to differentiate by culturing in an osteogenic media supplemented by $5 \mathrm{mM} \beta$-glycerol-phosphate ( $\beta \mathrm{GP}$ ) and $25 \mu \mathrm{g} / \mathrm{ml}$ ascorbic acid (AA) for 7 days, changing the medium every other day. ${ }^{19}$ The different culture periods for these cells are due to the different level of ALP expression in both cells lines. ${ }^{18,19}$

\subsection{Cell Adhesion and Proliferation}

The adhesion assay was performed as reported previously. ${ }^{14,20}$ Briefly, cells were plated in DMEM-10\% FBS on a polymeric matrix at a seeding density of $10^{5}$ cells $/ \mathrm{ml}$, and allowed to adhere for $1 \mathrm{~h}$ at $37^{\circ} \mathrm{C}$. For proliferation studies, cells were cultured for $24 \mathrm{~h}$. At the end of the incubation period, osteoblasts were washed with PBS, fixed with methanol and stained with Giemsa as we have previously described. ${ }^{14}$ The number of cells on each scaffold was evaluated by optical microscopy, counting ten representative fields per film.

\subsection{Evaluation of Markers for Osteoblastic Phenotype}

The ability of the cells to express markers of osteoblastic phenotype associated with bone-forming capacity was evaluated by measurement of ALP activity at $24 \mathrm{~h}^{21}$ Briefly, cells were washed with PBS and solubilized in $0.5 \mathrm{ml} 0.1 \%$ Triton $\mathrm{X}-100$. Aliquots of this total cell extract were used for protein determination by the Bradford technique $^{22}$ and for measurement of ALP activity by spectrophotometric determination of initial rates of hydrolysis of para-nitrophenyl-phosphate (p-NPP) to paranitrophenol (p-NP) at $37{ }^{\circ} \mathrm{C}$ for $10 \mathrm{~min}$. The production of p-NP was determined by absorbance at $405 \mathrm{~nm}$. Under our experimental conditions p-NP production was linear for $15 \mathrm{~min}$. 


\subsection{Statistical Analysis}

Results are expressed as mean \pm SEM and, unless indicated otherwise, were obtained from two separate experiments performed in triplicate. Differences between the groups were assessed by one-way ANOVA with Tukey post-hoc test. For non-normal distributed data, a non-parametrical Kruskal-Wallis with Dunn post-hoc test was performed using GraphPad In Stat version 3.00 (Graph Pad Software). A $p$ value $<0.05$ was considered significant for all statistical analyses.

\section{RESULTS AND DISCUSSION}

\subsection{Characterization of Films and Scaffolds}

Figures 2(a) and (b) shows the surface morphology of solution-cast films. Micrographs revealed a smooth surface with the presence of voids and typical spherulite-like morphology, as described in previous studies. ${ }^{15,23}$

The morphology of the structures obtained by electrospraying was also examined by SEM (Figs. 2(c and d)). The concentration and viscosity of the PCL/PDIF solution used in the electrospraying process was low enough to avoid micro/nanofiber formation. Electrospraying produced a homogeneous and uniform microparticle deposition over glass substrates. In the experimental conditions of this work, polymer microparticles of uniform size $(6.7 \pm 0.1 \mu \mathrm{m}$ in diameter) were obtained. The layers of randomly deposited droplets generated a three-dimensional scaffold with high porosity and interconnected pore structure that improve cell incorporation into the scaffold, as demonstrated in the next Section. This fact is extremely important, due to in other porous structures such as electrospun nanofibrous scaffolds, cell infiltration or permeability is difficult to achieve, requiring additional strategies to allow cell incorporation. ${ }^{8}$

The wetting of porous solids involves contact angle phenomena but is complicated by the presence of porous or textured architectures. ${ }^{24-26}$ The roughness and porosity affect dramatically the contact angle. WCA measurements revealed a significant difference between the contact angle values of flat film $\left(74^{\circ} \pm 1^{\circ}\right)$ and porous scaffolds $\left(132^{\circ} \pm 1^{\circ}\right)$. Air pockets are trapped below the liquid, inducing a composite interface between the solid and the drop. A drop eventually sits on a patchwork of solid and air, given rise to the measurement of an apparent contact angle with more hydrophobic character. Quantitative details of this behavior are extremely complex because of the very intricate structure of real porous media, ${ }^{26}$ and they are out of the scope of this work. However, these apparently more hydrophobic surfaces could affect, at least initially the attachment of cells. Consequently, the growth and development of osteblasts it is expected to be modulated (a)

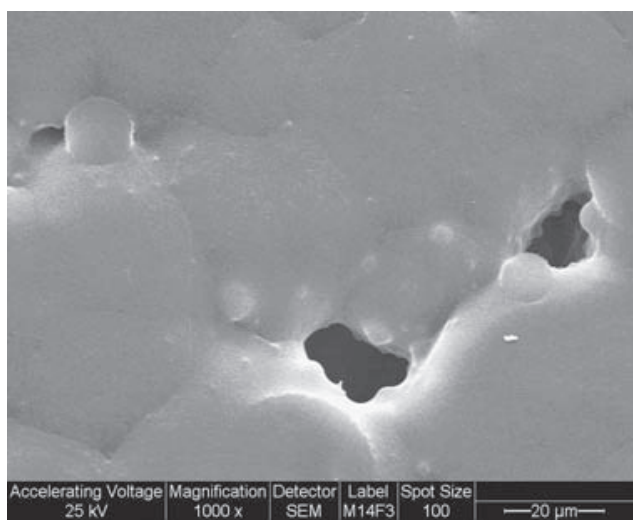

(c)

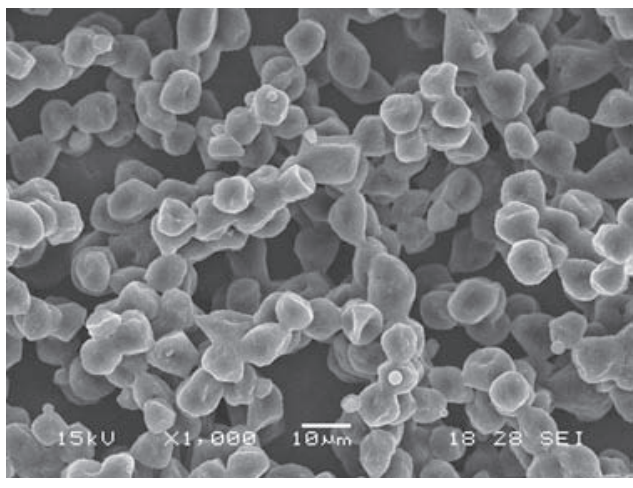

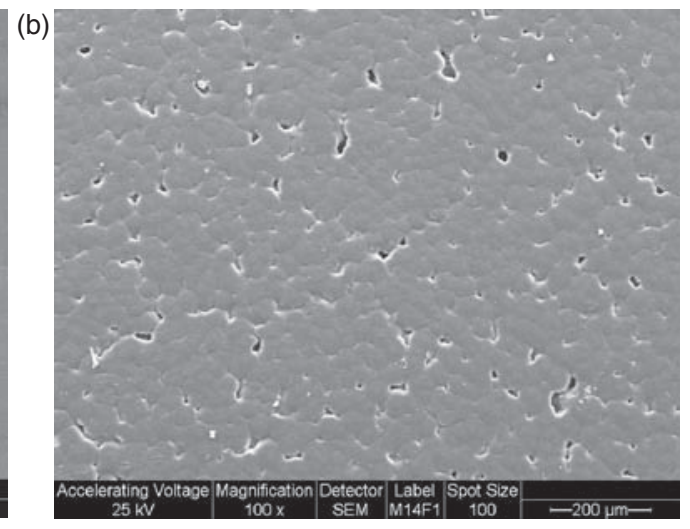

(d)

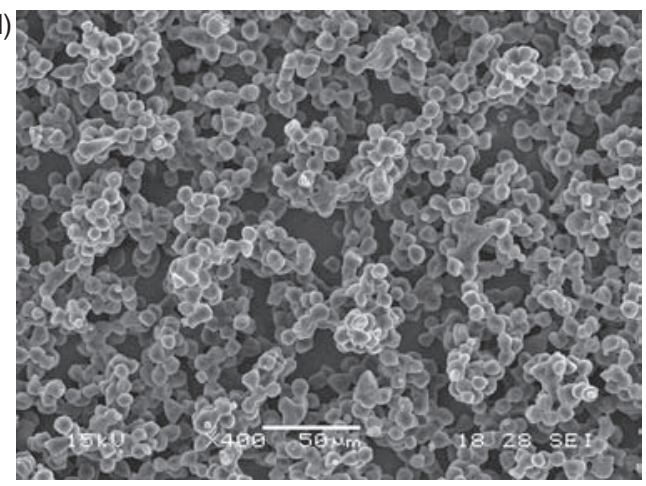

Fig. 2. Scanning electron micrographs showing the surface morphology of PCL/PDIPF systems: (a) and (b) solution-cast films at $1000 \times$ and $100 \times$ magnification, respectively; (c) and (d) glass substrates covered with multilayers of microparticles formed by electrospraying, at $1000 \times$ and $400 \times$ magnification. 
by the hydrophobicity and topographic characteristics of the surfaces.

\subsection{In Vitro Cell Studies}

In order to investigate the effect of topography of films and scaffolds on the biocompatibility response, two osteoblastlike cell lines were used to study their adhesion, proliferation and expression of the enzyme alkaline phosphatase, as a marker of osteoblastic differentiation.

The aspect and quantitative analysis of osteoblast number attached to both film and scaffold is displayed in Figure 3. Giemmsa staining shown that the cells adhered well to either the film or the electrosprayed scaffold. After one hour incubation, osteoblast look rounded in shape and appear in discrete areas of the films. However, when cells were seeded onto the scaffolds, more cells can be seen. In addition it was evident that osteblasts attached to the
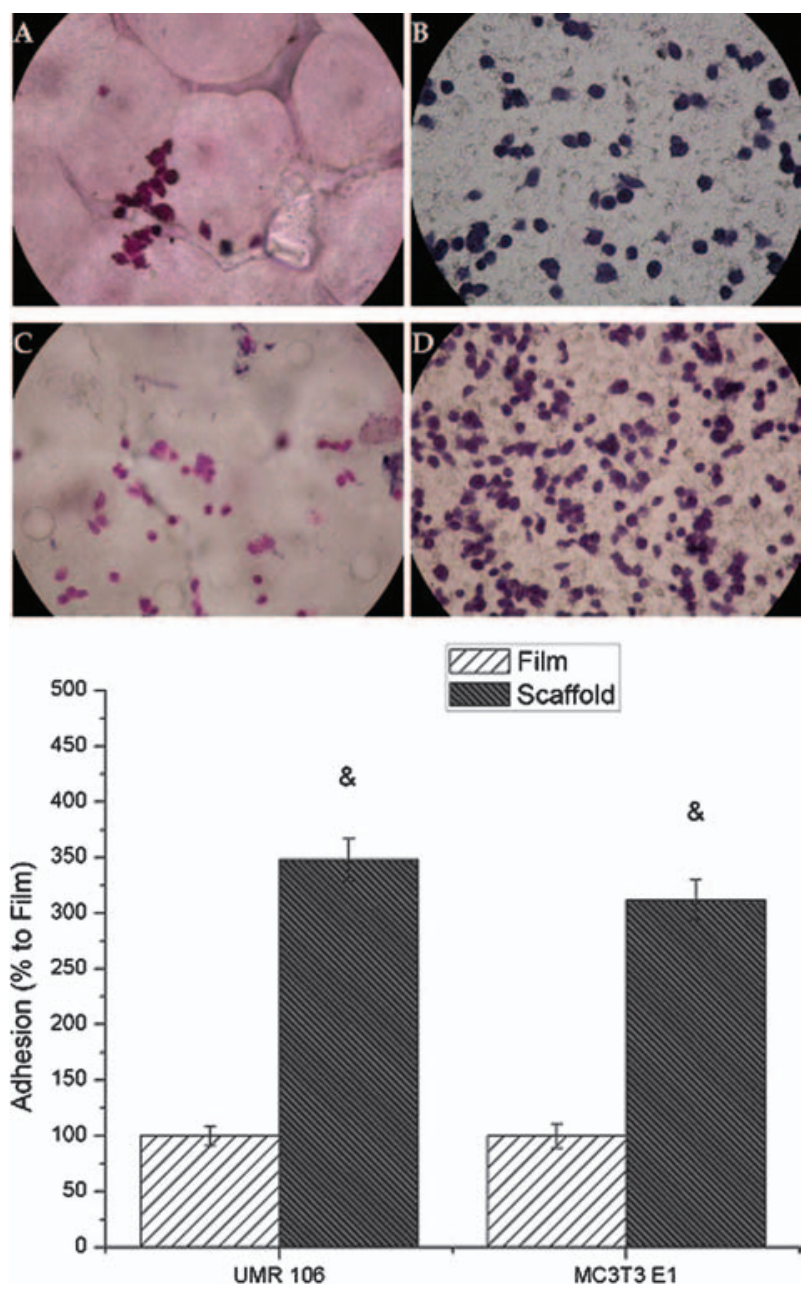

Fig. 3. Adhesion of UMR106 (A, B) and MC3T3E1 (C, D) osteoblasts plateled over the solvent-cast films (A; C) and the electrosprayed scaffold (B; D). Cells were incubated for $1 \mathrm{~h}$ and stained with Giemsa. The cells in ten fields per samples were counted and expressed as percentage of the cells in the cast film. Results are expressed as mean \pm SEM. $\&: p<0.01$. complete surface in a homogeneous manner. The quantification of these observations is shown in the lower panel of the Figure 3, demonstrating the statistically more cells (about 3 fold) were adhered to the porous scaffolds. These observations suggest that a porous and more hydrophobic matrix is promoting a strong adhesion of osteoblasts.

To determine whether weaker adhesion strength could affect the cells growth or result in the differential expression of osteogenic markers, we used osteoblast on both film and scaffold and evaluated proliferation and ALP expression. Figure 4 shows the morphology and number of osteblasts grown in both film and scaffold after $24 \mathrm{~h}$ of culture. It can be see that UMR106 and MC3T3E1 cells show spreading and process connecting each other in both surfaces. However, in the electrosprayed scaffold the number of growing cells is significantly increased in comparison to solvent-cast films (2-3.7 folds for MC3T3E1 and UMR106 cells, respectively).
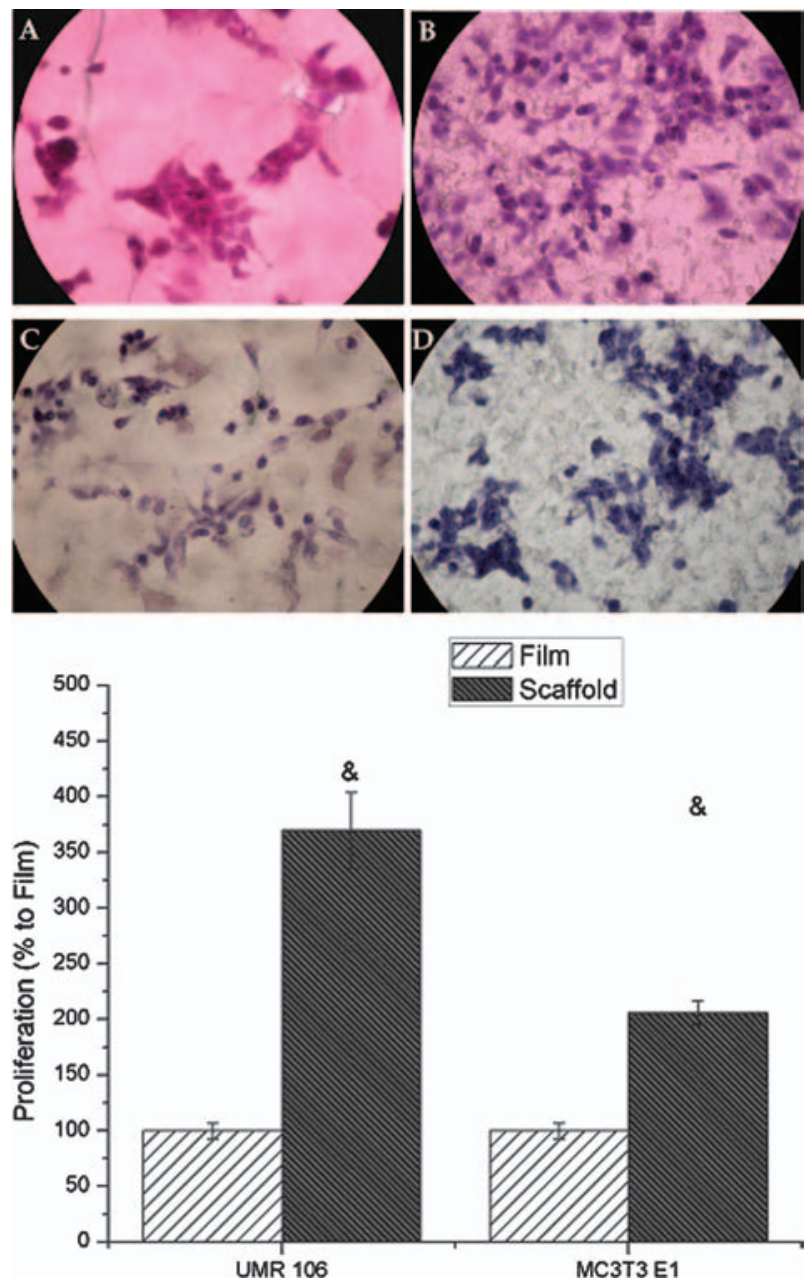

Fig. 4. Proliferation of UMR106 (A, B) and MC3T3E1 (C, D) osteoblasts plateled over the solvent-cast films $(\mathrm{A} ; \mathrm{C})$ and the electrosprayed scaffold (B; D). Cells were cultured for $24 \mathrm{~h}$ and stained with Giemsa. The cells in ten fields per samples were counted and expressed as percentage of the cells in the cast film. Results are expressed as mean \pm SEM. \&: $p<0.01$. 


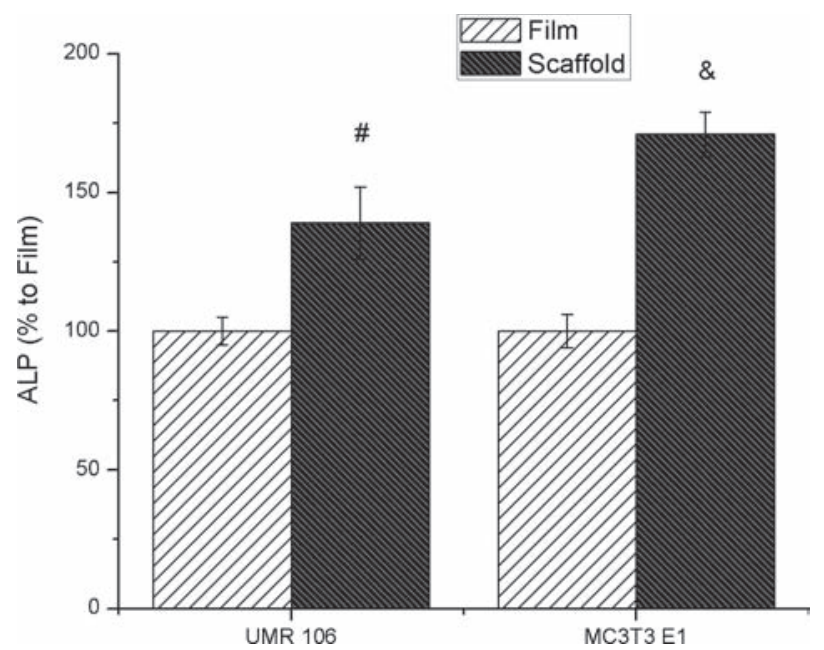

Fig. 5. ALP of cells UMR 106 and MC3T3 E1 over the electrosprayed scaffold and solvent-cast films. Cells were cultured for 2 (UMR106) or 7 days (MC3T3E1). After this culture period, cells were extracted and the ALP evaluated as described in Materials and Methods. The activity is expressed as $\%$ of cast film and represent the mean \pm SEM. $\&: p<0.01$; $\#: p<0.05$.

Finally, the ability to differentiate and express ALP, a marker of osteoblastic activity, was investigated by culturing UMR106 and MC3T3E1 cells during 2 or 7 days, respectively on film or scaffolds. When grown on the film, the ALP expression of UMR106 cells was of $233 \mathrm{nmol}$ p-NP/min.mg protein, while the ALP level for MC3T3E1 was of $2.1 \mathrm{nmol} \mathrm{p-NP/min.mg} \mathrm{protein.} \mathrm{Beside} \mathrm{these} \mathrm{differ-}$ ences, both osteoblastic lines were induced to express significantly more ALP when growing on the electrosprayed scaffold than on the casted film, as showed in Figure 5.

The cellular behaviour on biomaterials is a crucial factor for the evaluation of the biocompatibility of a biomaterial. This novel scaffold is characterized for a rough and porous although more hydrophobic surface. However, these properties are able to enhance the adhesion, proliferation and differentiation of the osteoblast in culture. Other authors have previously associated the porosity or the hydrophobicity with the biocompatibility of different materials. Our present results, however do not agree the general finding that hydrophobic materials do not support adhesion and spreading of cells. ${ }^{27}$ Nevertheless, other authors have been demonstrated that even when materials are relatively hydrophobic, osteblasts can growth and differentiated and mineralize the culture. ${ }^{28}$

All together these results suggest that scaffolds prepared by electrospraying of polymer solutions may be helpful in improving osteoblastic growth and in turn in osteointegration.

\section{CONCLUSIONS}

Highly porous scaffolds of PCL/PDIFP blend were successfully produced by microparticle deposition through electrospraying technique. These scaffolds exhibit a different topographic characteristic in comparison with solutioncast films as well as porous scaffolds obtained by other classical techniques.

In vitro cell culture experiments suggest that the threedimensional electrosprayed scaffold offered favorable surface topography and osteoinductive environment for the attachment and growth of osteoblast-like cells, the scaffold being more osteogenic than films of the same blend. These porous structures may potentially be used in bone tissue engineering.

Acknowledgments: This work was partially supported by grants from Facultad de Ciencias Exactas, Universidad Nacional de La Plata (UNLP), Comisión de Investigaciones Científicas de la Provincia de Buenos Aires (CICPBA) and Agencia Nacional de Promoción Científica y Técnológica (Grants BID-1728/OC-AR, PAE 22398, and PICT 448). Juan Manuel Fernandez thanks to CONICET for the fellowship awarded. Ana M. Cortizo is a member of the Carrera del Investigador of CICPBA.

\section{References and Notes}

1. P. X. Ma, Biomimetic materials for tissue engineering. Adv. Drug Del. Rev. 60, 184 (2008).

2. B. P. Chan, and K. W. Leong, Scaffolding in tissue engineering: General approaches and tissue-specific considerations. Eur. Spine J. 17, S467 (2008).

3. K. J. L. Burg, S. Porter, and J. F. Kellam, Biomaterial developments for bone tissue engineering. Biomaterials 21, 2347 (2000).

4. K. F. Leong, C. M. Cheah, and C. K. Chua, Solid freeform fabrication of three-dimensional scaffolds for engineering replacement tissues and organs. Biomaterials 24, 2363 (2003).

5. C. J. Bettinger, J. T. Borenstein, and R. Langer, Principles of Tissue Engineering, edited by R. P. Lanza, R. Langer, and J. Vacanti, Academic Press, San Diego, CA (2007), Chap. 24, pp. 341-358.

6. Y. Wu and R. L. Clark, Electrohydrodynamic atomization: A versatile process for preparing materials for biomedical applications. J. Biomater. Sci. Polymer Edn. 19, 573 (2008).

7. S. Chakraborty, I.-Ch. Liao, A. Adler, and K. W. Leong, Electrohydrodynamics: A facile technique to fabricate drug delivery systems. Adv. Drug. Del. Rev. 61, 1043 (2009).

8. V. Beachley and X. Wen, Polymer nanofibrous structures: Fabrication, biofunctionalization, and cell interactions. Progr. Polym. Sci. 35, 868 (2010).

9. A. Greiner and J. H. Wendorff, Electrospinning: A fascinating method for the preparation of ultrathin fibers. Angew. Chem. Int. Ed. Engl. 46, 5670 (2007).

10. P. C. Caracciolo, F. Buffa, V. Thomas, Y. K. Vohra, and G. A. Abraham, Biodegradable Polyurethanes: Comparative study of electrospun scaffolds and films. Journal of Applied Polymer Science 121, 3292 (2011).

11. N. Arya, S. Chakraborty, N. Dube, and D. S. Katti, Electrospraying: A facile technique for synthesis of chitosan-based micro/nanospheres for drug delivery applications. J. Biomed. Mat. Res. Part B. Appl. Biomater. 88B, 17 (2009).

12. S. G. Kumbar, S. Bhattacharyya, S. Sethuraman, and C. T. Laurencin, A preliminary report on a novel electrospray technique for nanoparticle based biomedical implants coating: Precision electrospraying. J. Biomed. Mat. Res. Part B. Appl. Biomater. 81B, 91 (2007). 
13. P. A. Gunatillake and R. Adhikari, Biodegradable synthetic polymers for tissue engineering. Eur. Cells and Mater. 5, 1 (2003).

14. M. S. Cortizo, M. S. Molinuevo, and A. M. Cortizo, Biocompatibility and biodegradation of polyesters and polyfumarates based-scaffold for bone tissue engineering. J. Tissue Eng. Regen. Med. 2, 33 (2008).

15. J. M. Fernandez, M. S. Molinuevo, A. M. Cortizo, A. D. McCarthy, and M. S. Cortizo, Characterization of poly(epsiloncaprolactone)/polyfumarate blends as scaffolds for bone tissue engineering. J. Biomat. Sci. Polym. Ed. 21, 1297 (2010).

16. M. S. Cortizo, Polymerization of diisopropyl fumarate under microwave irradiation. J. Appl. Polym. Sci. 103, 3785 (2007).

17. A. D. McCarthy, S. B. Etcheverry, L. Bruzzone, and A. M. Cortizo, Effects of advanced glycation end-products on the proliferation and differentiation of osteoblast-like cells. Mol. Cell. Biochem. 170, 43 (1997).

18. N. C. Partridge, D. Alcorn, V. P. Michelangeli, G. Ryan, and T. J. Martin, Morphological and biochemical characterization of four clonal osteogenic sarcoma cell lines of rat origin. Cancer Res. 43, 4308 (1983).

19. L. D. Quarles, D. A. Yahay, L. W. Lever, R. Caton, and R. J. Wenstrup. Distinct proliferative and differentiated stages of murine MC3T3-E1 cells in culture: an in vitro model of osteoblast development. J. Bone Miner. Res. 7, 683 (1992).

20. A. D. McCarthy, T. Uemura, S. B. Etcheverry, and A. M. Cortizo, Advanced glycation endproducts interfere with integrin-mediated osteoblastic attachment to a type-I collagen matrix. Int. J. Biochem. Cell Biol. 36, 840 (2004).
21. A. M. Cortizo, M. S. Molinuevo, D. A. Barrio, and L. Bruzzone, Osteogenic activity of vanadyl(IV)-ascorbate complex: evaluation of its mechanism of action. Int. J. Biochem. Cell Biol. 38, 1171 (2006).

22. M. M. Bradford, A rapid and sensitive method for the quantitation of microgram quantities of protein utilizing the principle of protein-dye binding. Anal. Biochem. 72, 248 (1976).

23. J. M. Fernandez, M. S. Molinuevo, M. S. Cortizo, and A. M. Cortizo, Development of an osteoconductive PCL-PDIPF hydroxyapatite composite scaffold for bone tissue engineering. J. Tissue. Eng. Regen. Med. 5, e126-35 (2011).

24. J. Bico, U. Thiele, and D. Quéré, Wetting of textured surfaces. Colloids and Surfaces A: Physicochem. Eng. Aspects 206, 41 (2002).

25. D. Hołownia, I. Kwiatkowska, and J. Hupka, An investigation on wetting of porous materials. Physicochemical Problems of Mineral Processing 42, 251 (2008).

26. Marmur, Contact Angle, Wettability and Adhesion, edited by K. L. Mittal, VSP, Utrecht (2003), Vol. 3, pp. 373-383.

27. K. Webb, V. Hlady, and P. A. Tresco, Relative importance of surface wettability and charged functional groups on NIH $3 \mathrm{~T} 3$ fibroblast attachment, spreading, and cytoskeletal organization. J. Biomed. Mater. Res. 41, 422 (1998).

28. Z. M. Liu, Q. Gu, Z. K. Xu, and T. Groth, Synergistic effect of polyelectrolyte multilayers and osteogenic growth medium on differentiation of human mesenchymal stem cells. Macromol. Biosci. 10, 1043 (2010).

Received: $\mathrm{xx}$ Xxxx xxxx. Accepted: $\mathrm{xx}$ Xxxx xxxx. 